\title{
Tako-Tsubo cardiomyopathy or allergic acute coronary syndrome: that is the question
}

\author{
Michele Correale $\cdot$ Francesco Santoro $\cdot$ \\ Riccardo Ieva $\cdot$ Matteo Di Biase . \\ Natale Daniele Brunetti
}

Received: 19 January 2013/Accepted: 11 April 2013/Published online: 24 April 2013

(C) SIMI 2013

Dear Editor,

We read with great interest the article by Fassio et al. [1] which provided a detailed review on Kounis syndrome (allergic acute coronary syndrome). The authors approached the issue both from the cardiologist's and the allergist's view.

Authors report that initial descriptions of Kounis syndrome were focused on patients with "angiographycally" normal coronary arteries and acute release of allergic mediators (histamine or leukotrienes); the prognosis of these patients is good, with the left ventricular function normalizing over 3 days to several weeks [2].

However, we recently reported a case (a 70-year-old woman) of transient apical ballooning (Tako-Tsubo syndrome) [3], with mild ST-elevation in anterior leads and increased troponin-I levels $[1.09 \mathrm{ng} / \mathrm{ml}$ (n.v. $<0.03)]$, triggered by administration of antibiotics (cephalosporin) in a patient with history of asthma and allergy. Tako-Tsubo syndrome is characterized by acute onset of chest symptoms, ECG changes with elevated cardiac markers mimicking acute myocardial infarction, left ventricular wall motion abnormalities in the apical region with preserved function of base, and normal coronary arteries [4]. Those affected are typically older women presenting after a stressful trigger, either emotional or physical.

According to authors' opinion, could there be a link between Kounis syndrome's variant with "angiographycally" normal coronary arteries and Tako-Tsubo syndrome triggered by administration of drugs in patient with history of asthma and allergy?

Conflict of interest None.

\section{References}

1. Fassio F, Almerigogna F (2012) Kounis syndrome (allergic acute coronary syndrome): different views in allergologic and cardiologic literature. Intern Emerg Med 7:489-495

2. Biteker M (2010) Current understanding of Kounis syndrome. Expert Rev Clin Immunol 6:777-788

3. Santoro F, Correale M, Ieva R, Caiaffa MF, Pappalardo I, Di Biase M, Brunetti ND (2012) Tako-Tsubo cardiomyopathy following an allergic asthma attack after cephalosporin administration. Int J Cardiol 159:e20-e21

4. Donohue D, Movahed MR (2005) Clinical characteristics, demographics and prognosis of transient left ventricular apical ballooning syndrome. Heart Fail Rev 10:311-316
M. Correale $(\bowtie) \cdot$ F. Santoro $\cdot$ R. Ieva $\cdot$

M. D. Biase - N. D. Brunetti

Department of Cardiology, "Ospedali Riuniti”OO.RR, University of Foggia, viale L Pinto, 1, 71100 Foggia, Italy

e-mail: opsfco@tin.it 